\title{
قضية خلق القرآن عند الجبرية والمعتزلة وأهل السنة
}

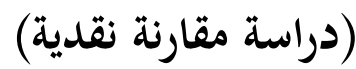

\author{
Amir Sahidin \\ Universitas Darussalam (UNIDA) Gontor Ponorogo Jawa Timur \\ Email: amirsahidin42003@mhs.unida.gontor.ac.id
}

\begin{abstract}
Abdul Rohman
Universitas Darussalam (UNIDA) Gontor Ponorogo Jawa Timur

Email: ilmanhaq9@gmail.com
\end{abstract}

\section{Abstract:}

The discussion of khalqul qur'an is a very crucial issue among the Mutakallimin. The Jabariyyah and Mu'tazilah groups say that the Qur'an is a creature in order to purify Allah from human-like characteristics. In fact, saying khalqul qur'an (the Qur'an is a creature) is the same as negating the nature of God, in the form of kalam. Belief like this will lead to three imperatives: first, as if God as the essence of the nature is a creature. Second, Allah is a mute Rabb, while being mute is a deficiency trait. Third, Allah's knowledge is a creature, because the Qur'an is His knowledge, then how could Allah have created knowledge first in order to have knowledge. Therefore the scholars of the Ahli Sunnah are unanimously agreed that the Qur'an is kalamullah. Among the scholars of the Ahli Sunnah who are very firm in defending the beliefs of the Sunnah are Imam Ahmad bin Hanbal. He not only gave strong arguments, but also refuted the group that said khalqul qur'an with a solid rebuttal. Based on a qualitative method and a comparative critical approach, it was found that, first, Jabariyyah and Mu'tazilah agreed that the Qur'an was a creature. Second, the Sunnah experts in general and Imam Ahmad bin Hanbal in particular insist that the Qur'an is the kalamullah. Third, when their arguments are found, the strongest is the opinion of the Ahli Sunnah. The basis for this 
204 Rausyan Fikr, Vol. 17 No. 2 Desember 2021: 203 - 227.

difference of opinion is based on their beliefs about the nature of Allah.

Pembahasan tentang khalqul qur'an merupakan persoalan yang sangat krusial di antara para Mutakallimin. Kelompok Jabariyyah dan Mu'tazilah mengatakan bahwa Al-Qur'an adalah makluk agar munsucikan Allah dari sifat-sifat yang menyerupai manusia. Padalah mengatakan khalqul qur'an (Al-Qur'an adalah makhluk) sama saja meniadakan sifat Allah, berupa kalam. Keyakinan seperti ini akan menggiring kepada tiga keharusan: pertama, seakan-akan Allah sebagai Dzat yang disifati adalah makluk. Kedua, Allah merupakan Rabb yang bisu, sedangkan bisu termasuk sifat kekurangan. Ketiga, ilmu Allah adalah makluk, karena Al-Qur'an adalah ilmu-Nya, maka bagaimana mungkin Allah harus menciptkan ilmu terlebih dahulu agar memiliki ilmu. Karenanya para ulama Ahli Sunnah sepakat bahwa Al-Qur'an adalah kalamullah. Di antara ulama Ahli Sunnah yang sangat teguh dalam membela keyakinan Ahli Sunnah ini adalah Imam Ahmad bin Hanbal. Ia tidak hanya memberikan argumentasi kuat, melainkan juga membantah kelompok yang mengatakan khalqul qur'an dengan bantahan yang kokoh. Berdasakan metode kualitatif dan pendekatan kritis komparatif ditemukan bahwa, pertama, Jabariyyah dan Mu'tazilah sepakat bahwa Al-Qur'an adalah makluk. Kedua, Ahli Sunnah secara umum dan khususnya Imam Ahmad bin Hanbal besikukuh bahwa Al-Qur'an adalah kalamullah. Ketiga, ketika argementasi mereka ditemukan, maka yang terkuat adalah pendapat Ahli Sunnah. Landasan perbedaan pendapat ini didasari oleh keyakinan mereka tentang sifat Allah.

Kata Kunci: Khalqul Qur'an, Jabariyyah, Mu'tazilah, Ahli Sunnah, Ahmad bin Hanbal 
القول بخلق القرآن مشكلة خطيرة بين المتكلمين. وهذه المشكلة يعني القول بخلق القرآن من أهميّة البحث في قضية علم الكلام. لأن القول بأن القرآن مخلوق يلزم إلى نفي الصفة من صفات الله وهي الكلام. والقول بأن الصفات

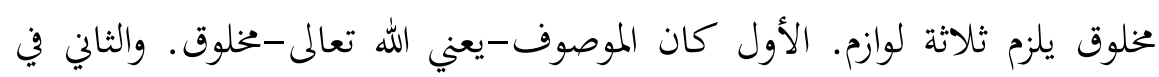
نفي صفات الكلام قد وصّف الله بالأَبكم، وهو من صفات النقائص. والثالث في تلان

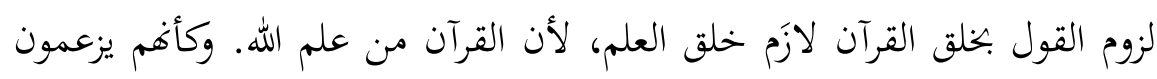
أن الله لم يكن عالما حتى خلَق العلم. 1 ومُّن قال أن القرآن مخلوق هو الجبرية والمعتزلة. هم يقولون مثل ذلك الكم لأجل التنزيه الى الله من الصفات. لأن الصفات عندهم من الحوادث. والسبب في هذه المغالطة لأفم استدلّوا بالتأويل الكلامي وبالدليل العقلي يعني تقديم العقل

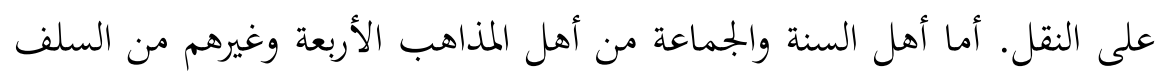

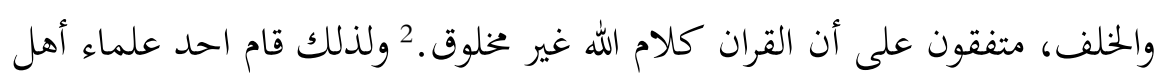
السنة والجماعة، وهو الإمام أحمد ابن حنبل لرد القول بخلق القرآن. وهو يرد ردا شديدا في المناقشة الطويلة بينه وبين الجبرية والمعتزلة، حتى يصيب المحنة في العصر الطويل منذ عصر الخليفة المؤمون والمعتصم والواثق.

1 عبد العزيز بن مرزوق الطرف، الحراسانية في شح عقيدة الرازيين، ج.1، (د.م: مكتبة المنهاج،

$$
\text { 2016 م)، ص. 175-178 }
$$

22 عبد الاخر حماد الغنيمي، المنحة الإلهية في تمديب شرح الطحاوية، (بيروت: دار ابن الجوزي،

1995)، ص. 119 
206 Rausyan Fikr, Vol. 17 No. 2 Desember 2021: 203 - 227.

وزيادة على ذلك، فإن مشكلة خلق القرآن هي أيضا مشكلة معاصرة وإن كان في شكل أشد خطورة، ألا وهو افتراض أن القرآن نص بشري ومنتج ثقافي كما قال نصر حامد أبو زيد. 3كل هذه اقتراضات خاطئة ومضللة بالتأكيد، وأوضح وهبة الزهيلي أن القرآن كلام الله تعالى بتنظمه ومعناه.4 وإذا قيل أن القرآن منتج ثقافي، فمن المؤكد أن القرآن لن ينكره المشركون في ذلك الوقت. لكن على العكس تمامًا، يعتبر القرآن سحرًا حقيقيًا، 5 ويأمر القرآن بترك الثقافات الجاهلة، مثل شرب الحمر، والمقامرة، والتضحية للأوثان، ورسم القدر بالسهام، وغيرها في ذلك الوقت.6 فكل هذه تدل على أهمية البحث عن القرآن، خاصة في رد الشبهة والشكوك فيه. وكان من أول الشبهة تتعلق بالقرآن يعني شبهة خلق القرآن. من هذه خلفية البحث، أراد الباحث ان يقرن ويرد ما قاله الجبرية والمعتزلة في مسألة خلق القرآن بأراء أهل السنة والجماعة، خاصة قول الإمام أحمد بن حنبل. لأنه من كبار العلماء في عصره، ويعيش تحت شدة الفتنة والمحنة. وأكبر المحنة الذي عان الإمام أحمد بن حنبل في عصر خليفة المؤمون والمعتصم والواثق. استعمل الحليفة المؤمون قوّته أن يُجبِر الفقهاء والمحدّثتون ليواقفوا أن القرآن مخلوق. 7

3 نصر حامد أبو زيد، نقد الخطاب الديني، (القاهرة: سينا للنشر، 1994)، ص. 126. ونصر

حامد أبو زيد، مفاهم النص: دراسة في علوم القرآن، (بيروت: المركز الثقافي العربي، 2014) ص. 24

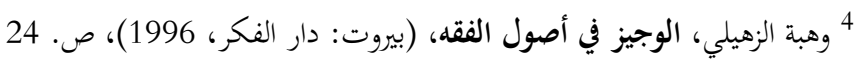

5

6

7 محمد أبو زهرة، ابن حنبل :حياته وعصره، آراءه وفقهه، (القاهرة: دار الفكر العربي، د.ع)، 
فلعلى هذا البحث نافعا لجميع المسلمين في العالم، ويكون دفعا لمن أصاب شبهة

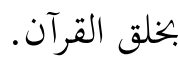

\section{التعريف عن خلق القرآن}

"خلق القرآن" في النحوي هو الإضافة من لفظين يعني "خلق" وهو

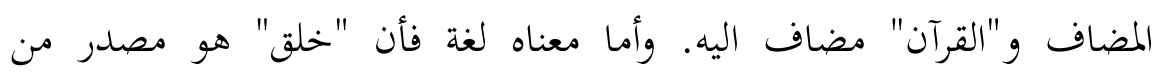

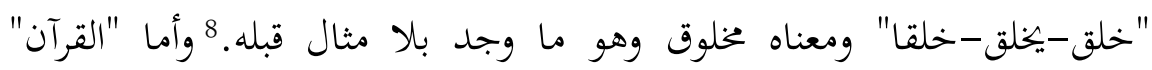

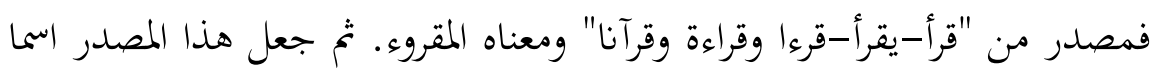

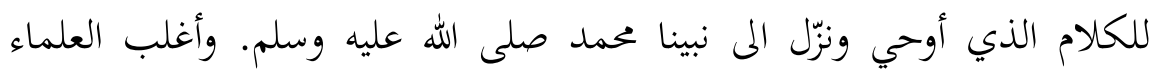
يتعرف القرآن كلام الله المعتجِز ونزّل المى رسول الله صلى الله عليه وسلم، وكتب في في النصوص، ونقل متوتّرا، والقراءة به عبادة.9 من هذين معنيين نعرف بأن المصطرلح

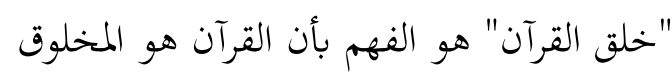

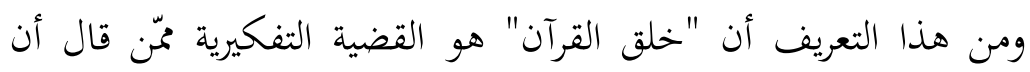
القرآن مخلوق ولا يُوصَف بصفة قديمة وأزلية. ونشأ هذ الرأي في دولة الأُمَيَّة ثم طرأ في أول دولة العباسية حتى جعله المؤمون والخليفتان بعده فهما رسميا في الدولة وهذا اشتهر بالمِحنَة.

\section{قضية الجبرية في خلق القرآن}

أما الجبرية أو الجهمية هم فرقة الكلامية التي نسبت إلى جهم بن صفوان، 10 الذي يقول بالجبر أي أن الإنسان مجبور في أفعاله وأنه لا اختيار له ولاني لهابه

\footnotetext{
8 ابن منظور، لسان العرب، ج. 11، (بيروت: دار الكتب العلمية، 2009 م)، ص. 102.

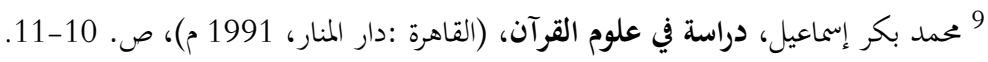

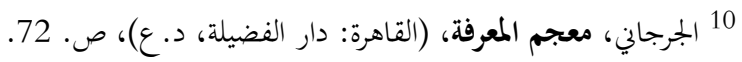


208 Rausyan Fikr, Vol. 17 No. 2 Desember 2021: 203 - 227.

قدرة، أنه كالريشة المعلقة في الهواء إذا هبت الريح تحرك يمينا وشثالا وإن لم تبب سكت، وإن الله سبحانه وتهالى قدر عليه أعمالا لابد أن تصدر منه. 11وتعلّم صفوان علم الكالام من جعد بن درهم. 12 أما مذهب الجبرية في تقرير العقيدة فهو تأويل آيات الصفات التي تؤدي إلى تشبيه بمخلوقاته، وأتمت صفة الفعل والخلق فتط ولا يصح أن يتصف المخلوقات بهاتين الصفتين.13 إنما اتفق جهم بن صفوان القول بخلق القرآن.14 والقول بخلق القرآن مرتبط ارتباطا وثيقا بنفي الصفات. لأن نفي الصفات عن الله تعالى يجر إلى نفي الكالام الذي لا يصدر عن جارحة. ولما كان تعالى منزها عن الصفات، فلا بد أن يقال على أنه تعالى خلق القرآن كما اتفق الجهم والمعتزلة.15 عند الجهم لا يجيوز أن الله تعالى بصفة يوصف بها خلقه لأن ذلك يقضي تشبيها. فنفى كونه حيا، عالما. أثبت كونه قادرا وفاعلا وخالقا. لأنه لا يوصف شيء من خلقه بالقدرة والفعل والخلق.

11 أمّل فتح الله زركشي، دراسة في علم الكلام، (فونوروكو :جامعة دار السلام كوتور للطباعة

$$
\text { والنشر، } 2016 \text { م)، ص. } 51
$$

12 محمد بن محمد بن عبد الرزّاق الحُسين مرتضى، تاج العروس من جوهر القاموس، (د.م :دار

الهداية، د.ع)، ص. 433.

13 أمّل فتح الله زركشي، المصدر السابق، ص. 51 ألمان 53

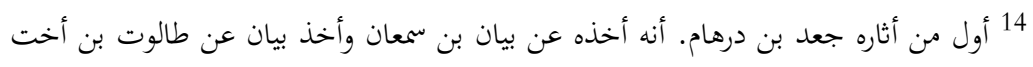

لبيد بن أعصم وأخذته لبيد بن أعصم الساحر الذي سحر رسول الله صلى الله عليه وسلم عن يهودي باليمن.

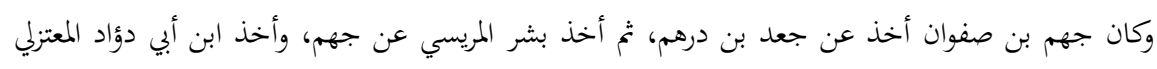

15 محمد إبراهيم الفيّومي، الحوارج والمرجئة، (القاهرة: دار الفكر العربي، 2003)، ص. 281عن بشر.

16 أمّل فتح الله زركشي، دراسة في علم الكلام، ص. 119-120. 
وأما استدلال الجبرية في زعمهم بأن القرآن مخلوق فمنها:

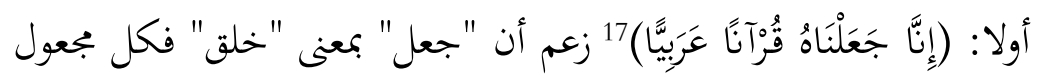
هو مخلوق.18 ثانيا: (اللهُ خَالِقُ كُكلَّ شَيٍْ) 19 والقرآن شيء يقع عليه اسم شيء، وهو مخلوق، لأن "كل" يجمع كل شيء.

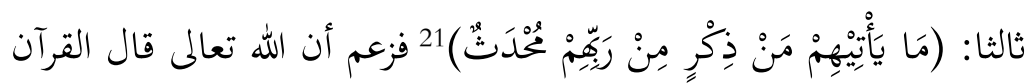
محدث بنسبة إلى لفظ "ذكر"، وكل محدث مخلوق.

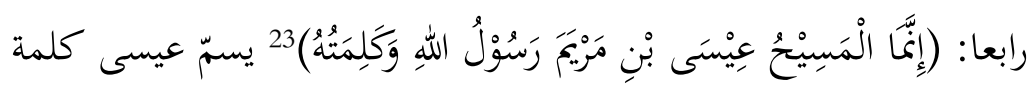
الله، وعيسى مخلوق. ولذلك القرآن مخلوق.24 من تلك الآيات أكّد الجبرية قولمم بأن القرآن مخلوقا، منزّه لله تعالى عن صفات الخلق وتوحيدا لذاته تعالى.$$
17
$$

18 أحمد بن حنبل، الرد على الجهمية والزنادقة، (الرياض: دار الثبات النشر والتوزيع، 2003

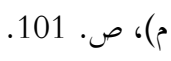$$
19 \text { سورة الزمر، آية } 63 .
$$$$
20 \text { أحمد بن حنبل، المصدر السابق، ص. } 113 .
$$$$
21
$$$$
22 \text { أحمد بن حنبل، المصدر السابق، ص. } 21 \text { الانياء، } 121 .
$$$$
23 \text { سورة النساء، آية } 171 .
$$$$
24 \text { أحمد بن حنبل، المصدر السابق، ص. } 125 .
$$ 
210 Rausyan Fikr, Vol. 17 No. 2 Desember 2021: 203 - 227.

\section{قضية المعتزلة في خلق القرآن}

أما المعتزلة فهي اسم يطلق على فرقة ظهرت في الإسلام في أوائل القرن

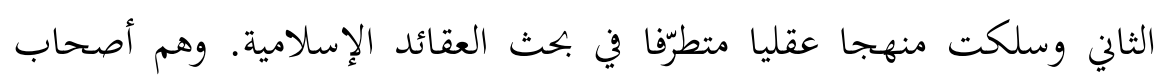

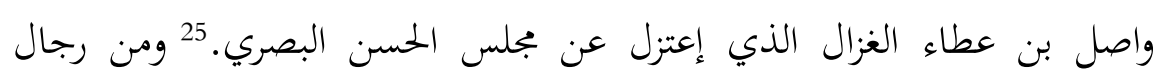

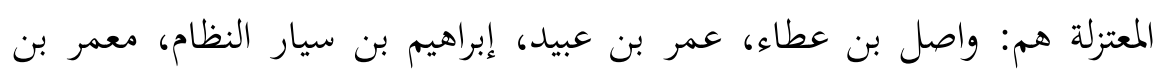

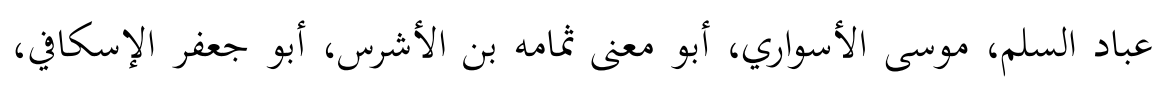
وغير ذلك.26

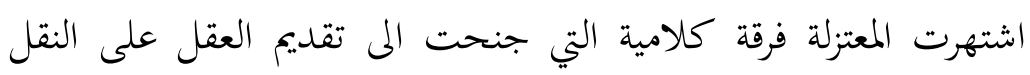

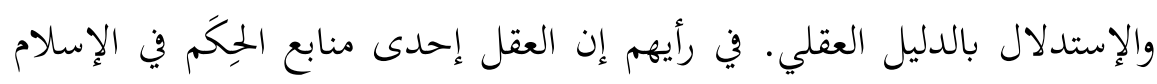

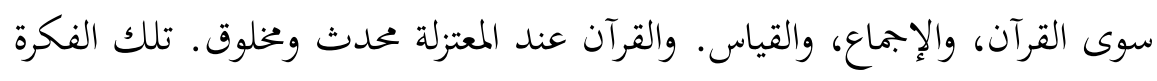
تنتمي الى قضية نفي الصفات عموما والتي تستند إلى مبدأ التوحيد المنزلي (التنزيه).

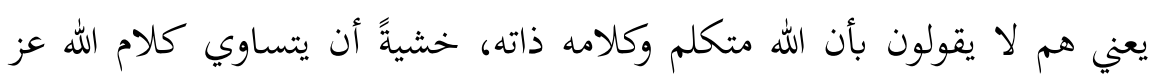

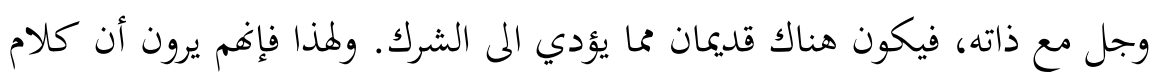

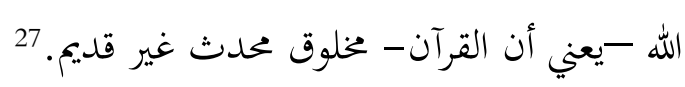

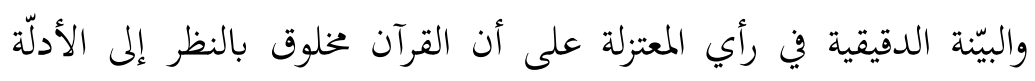

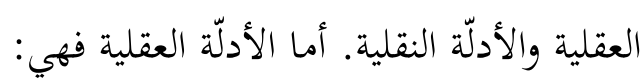

25 عوّاد بن عبد المعتق، المعتزلة وأصولم الحمسة وموقف أهل السنة منها، (الرياض: مكتبة

$$
\begin{aligned}
& \text { الرشد، } 1414 \text { هـ)، ص. 13-14. } \\
& 26 \text { أمّل فتح الله زركشي، دراسة في علم الكلام، ص. 113 -119-120. }
\end{aligned}
$$

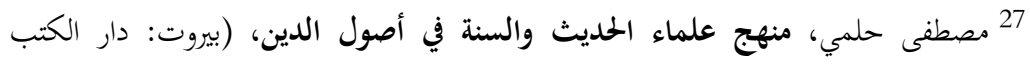


أولا: أنّ القرآن مقروء باللسان وممسوح باليد ومنظور بالعين ومسموع بالأذن. فمستحلّة لو هذا صفة الله، لأنّ الكلام بصفة الله لا يّّصف بصفات. ثانيا: إن كان الكلام صفة أزلية ليصبح القرآن قديما ولشارك الله في الإلهية. لأن القدم صفة الذات للألوهية. ثالثا: والخطاب لموسى مختلف بالخطاب لمحمّد. ومنهج الكلام لكل رسول مختلف. فمستحلّة إذا قيل "الكلام واحد". على أن شكله مختلف لكل بكل رسول. وهذا يتعارض بصفات الذات للألوهية. رابعا: أكّد المعتزلة وجود الشيء الذي يُحناطَب به. إذا نُصِّرِ بأن الله كلّم

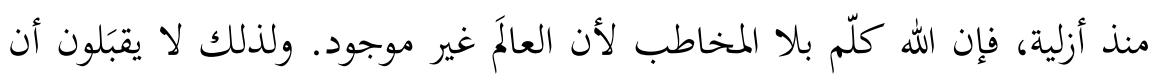
كلام الله أزلي وقديم. وكل غير قديم هو مخلوق. 31

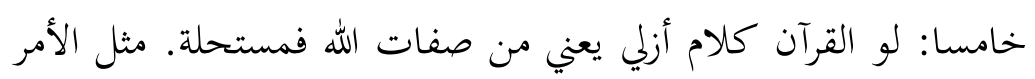
في القرآن لا يفيد إلا بوجود المأمور. ولذلك يستحل المأمور موجود في زمان أزلي. باعتبار الأمر بالصلاة الذي لمُ يكن مَن يقيمون الصلاة. 32

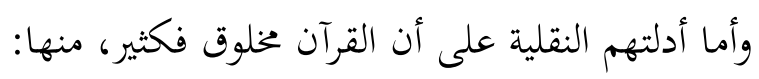

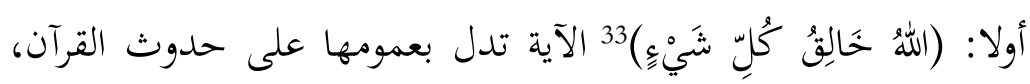
وأنه تعالى خلقه.34

28 القاضي عبد الجبار، المفني في أبواب التوحيد والعدل، ج. 7، (القاهرة: دار التراث، 1961

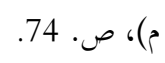

$$
\begin{aligned}
& 29 \text { أمّل فتح الله زركشي، دراسة في علم الكلام، ص. } 133 . \\
& 30 \text { نفس المرجع، ص. } 134 . \\
& 31 \text { أحمد أمين، ضحى الإسلام، (القاهرة: النحضة المصرية، } 1973 \text { م)، ص. } 1973 \\
& 32 \text { نفس المرجع، ص. } 35 .
\end{aligned}
$$


212 Rausyan Fikr, Vol. 17 No. 2 Desember 2021: 203 - 227.

ثانيا: (إِنَّا جَعَلْنَا قُرْآناً عَربيَّا) 35 الآية تدل على وجوب حدوثه، لأن الجمل

$$
\text { والفعل سواء في الحقيقة. } 36
$$

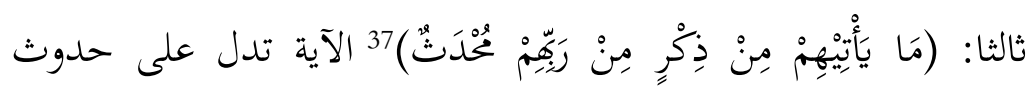
القرآن، لأنه تعالى نصّ على أن الذكر محدث.38 وبيّن بآية أخرى أن الذكر هو

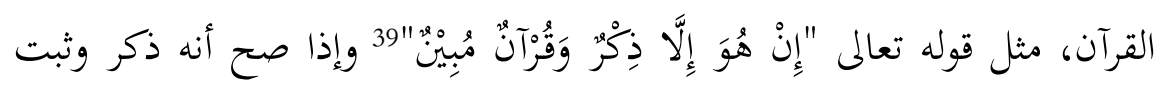
بهذه الآية حدوث الذكر، فقد وجب القول بحدوث القرآن.

رابعا: (وَمْنْ قَبْلِِهِ كِتَابُ مُوْسَى) 41 الآية تدل على كتاب منزل قبل القرآن يعني التوراة التي نزّلت على موسى عليه السلام. وما تقدم غيره يلزم حدوثه ولا يكون قديما.

خامسا: (قُلْ لَْ كَانَ الْبَحْرُ مِدَادًا لِكِلِمَاتِ رَبِّيْ لَنَفِدَ الْبَحْرُ قَبْلَ أَنْ تَنْفَدَ

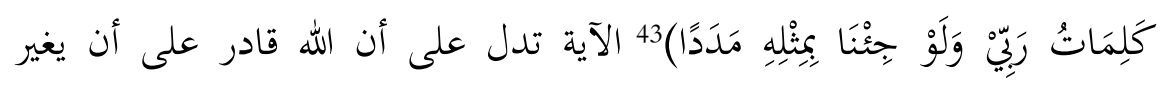

$$
33
$$

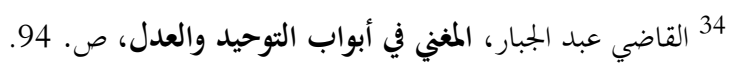

$$
35 \text { سورة الزخروف، آية 3. } 35 \text { القاضي عبد الجبار، المرجع السابق، ص. } 94
$$$$
37
$$

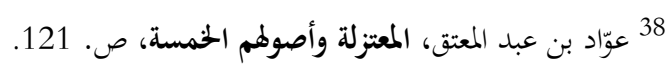

$$
39 \text { سورة يس، آية } 69 .
$$

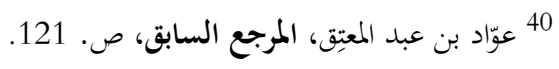

$$
41 \text { سورة هود، آية } 17 .
$$

$$
42 \text { أمّل فتح الله زركشي، دراسة في علم الكلام، ص. } 13 \text { صدود } 135 .
$$

$$
43 \text { سورة الكهف، آية } 109 .
$$


القرآن كله أو بعضه أو يُبِّله بغيره أو يأتي بمثله أو يزيد فيه. وما يتبدل ويتغير فهو محدث.44

والإستنتاج من حُجَج المعتزلة هناك أها تدلّ على قويّهم ومتناسقهم في

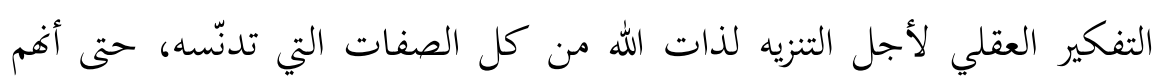
لاشكُّ بالقول على أن القرآن مخلوق. قضية أهل السنة والجماعة في خلق القرآن وبالجملة، فأهل السنة والجماعة من أهل المذاهب الأربعة وغيرهم من السلف والخلف، متفقون على أن القران كلام الله غير مخلوق.45 ومن أدلة أهل السنة في إثبات صفة الكلام لله فيما يالي:46

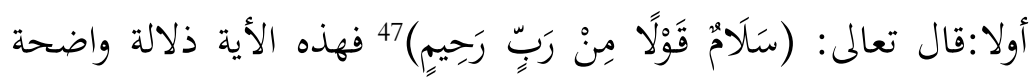
بأن القرآن هو كلام الله. ثانيا: قال تعالى: (وَكَلََّّم اللَّهُ مُوسَى تَكْلِيمًا) 48 أكد الله تعالى التكليم

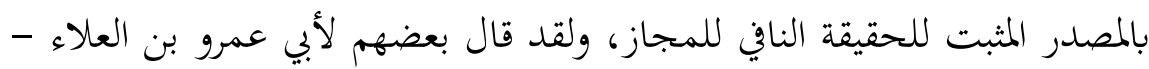

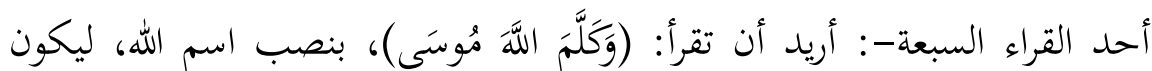

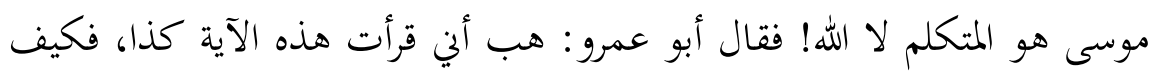

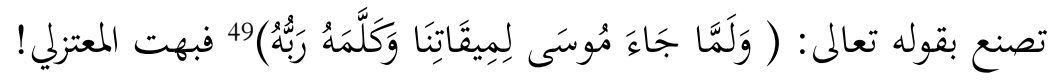

$$
44 \text { أمّل فتح الله زركشي، المرجع السابق، ص. } 135 .
$$

45 عبد الاخر حماد الغنيمي، المنحة الإلهية في تمديب شرح الطح الطحاوية، ص. صل 135

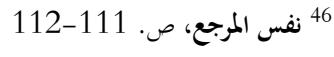

$$
\begin{aligned}
& 47 \text { سورة يس: } 48 \\
& 48 \text { سورة النساء: } 164 \\
& 49 \text { سورة الأعراف: } 143
\end{aligned}
$$


214 Rausyan Fikr, Vol. 17 No. 2 Desember 2021: 203 - 227.

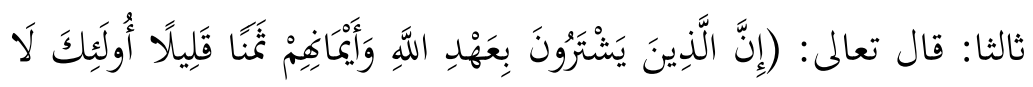

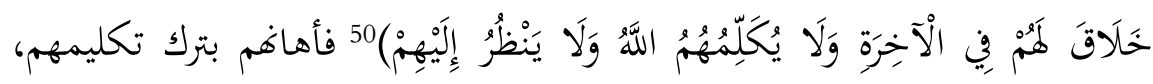

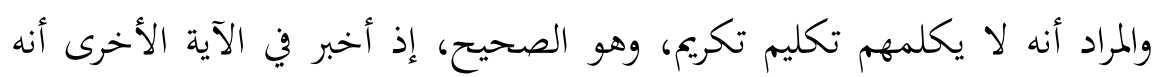

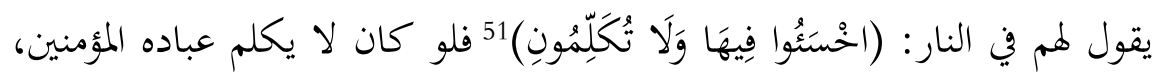

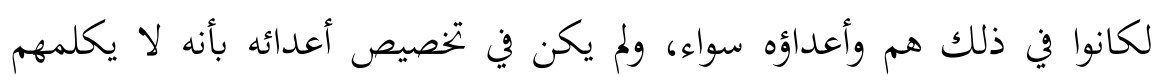
فائدة أصلا.

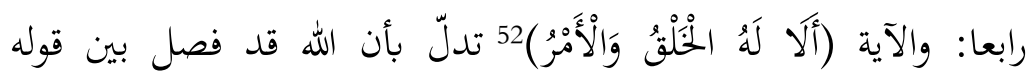

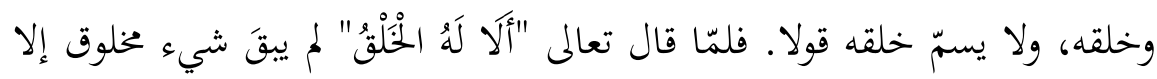

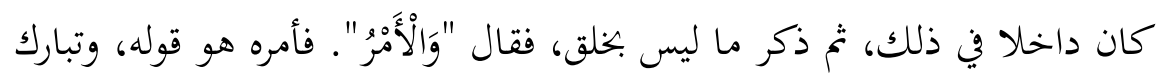
رب العالمين إن يكون قوله خلقا.53

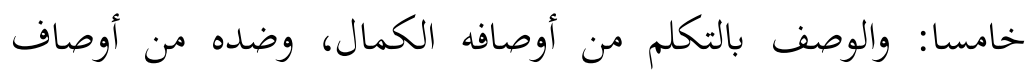

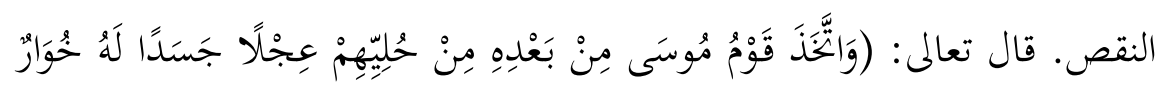

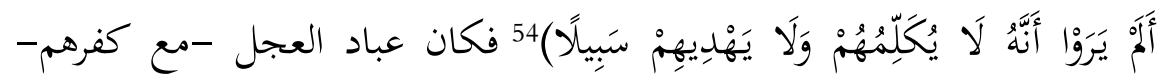

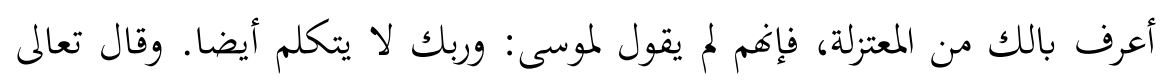

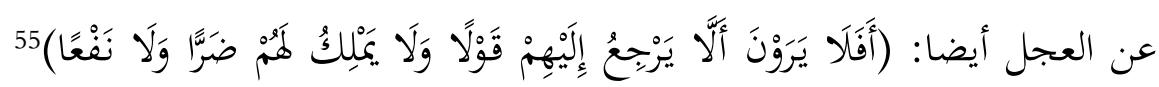

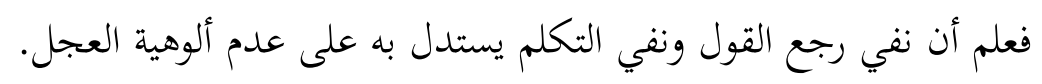

$$
\begin{aligned}
& 50 \\
& 51 \text { سورة المؤمنون: } 108 \\
& 52 \text { سورة الأعراف، آية } 54 .
\end{aligned}
$$

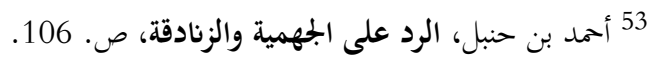

$$
\begin{aligned}
& 54 \text { سورة الأعراف: } 148 \\
& 55 \text { سورة طه: } 89
\end{aligned}
$$


سادسا: وقد كتب البخاري في صحيحه بابا خاصا، يعني باب كلام

$$
\text { الرب تبارك وتعالى مع أهل الجنة، وساق فيه عدة أحاديث.5 }
$$

ومن العلماء أهل السنة والجماعة له دور واثر كبير في رد فهم خلق القران

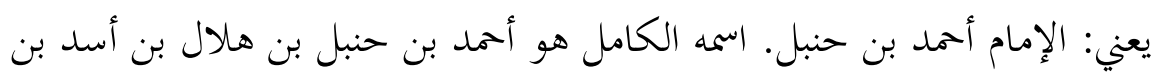

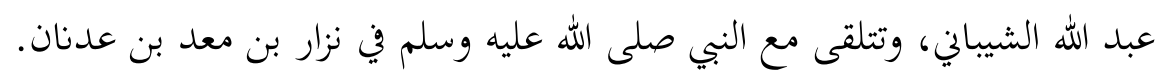

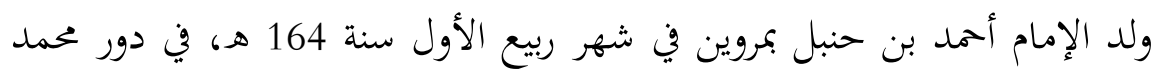

$$
\text { المهدي. ولكن في الطفولة أوردت أمه المى بغداد العراق. }
$$

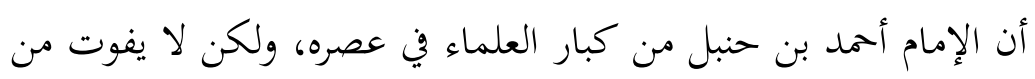
بعض البلوى. وأكبر البلوى الذي عانى الإمام هو في عصر خليفة المؤمون والمعتصم والواثق. استعمل الخليفة المؤمون قوّته ان يُجبِر الفقهاء والمحدّثون ليواقفوا أن القرآن مخلوق. وهذه الواقعة سميت "بالمحنة". 58 قد كان الإمام أحمد ينهج المنهج النقلي في تقرير العقيدة، وفي الصفات الإلهية قد التزم بما وصف الله به نفسه ووصفه به رسوله، بدون تشبيه ولا تعطيل،

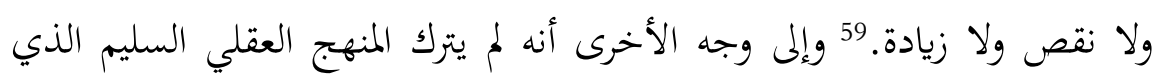

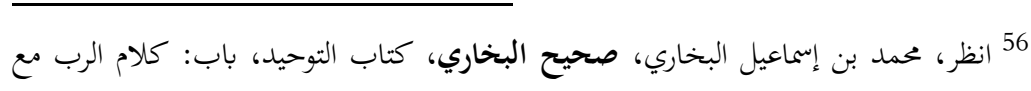

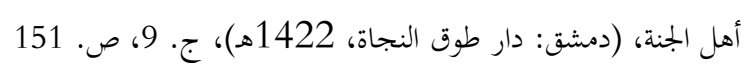

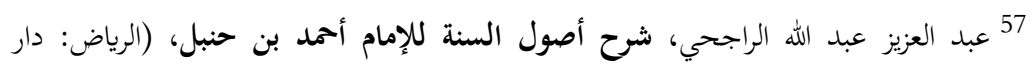

$$
\text { التوحيد للنشر، } 1434 \text { هـ)، ص. } 19 .
$$

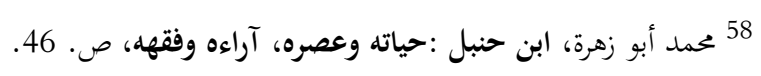

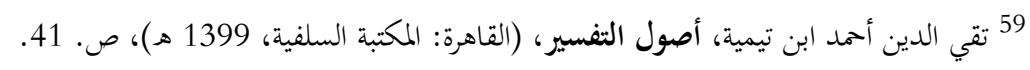


216 Rausyan Fikr, Vol. 17 No. 2 Desember 2021: 203 - 227.

حثّ عليه القرآن ودلّ عليه الحديث. وأنه قد اعتمد على أصول اللغة العربية ومواصفاها وقانوها في مخاطبة ومحاورة. 60 كان الإمام أحمد استقرّ على أن القرآن غير مخلوق. وهو ردّ ردّا صريحا كاملا على رأي الجبرية والمعتزلة بأن القرآن مخلوق. وأما ردّه إلى أدعاء الجبرية والمعتزلة فباستدلال بالآيات القرآنيات مع تفسير صحيح الدين سنبحث عنه فيما بعل.

\section{تحليل المقارنة والنقدي عن قضية خلق القرآن}

في هذا البحث حدد الباحث البيان في ثلاثة أوجه: الوجه الأول يعني وجه الإتفاق بين الجبرية والمعتزلة في المسألة خلق القران. الوجة الثاني يعني وجه الإختلاف بين الجبرية والمعتزلة وبين أهل السنة والجماعة وخاصة الإمام أحمد بن حنبل في تلك المسألة. والوجة الثالث يعني وجه النقدي أو الرد على الجبرية والمعتزلة في مسألة خلق القرآن. والبيان على ذالك فيما يلي:

أولا : وجه الإتفاق

وافق الجبرية والمعتزلة بأن القرآن مخلوق. تلك الفكرة تنتمي الى قضية نفي الصفات عموما والتي تستند إلى مبدأ التوحيد المعتزلي. هم لا يقولون بأن الله متكلم وكلامه ذاته خشيةً أن يتساوي كلام الله عز وجل مع ذاته. فيكون هناك قديمان محا يؤدي الى الشرك. ولا كان الله تعالى منزّها عن الصفات، في نظر الجبرية والمعتزلة 
فلا بد أن يوافق قول خلق القرآن. وهذا ما اعترف به المعتزلة أنفسهم، منذ أن أقرّوا

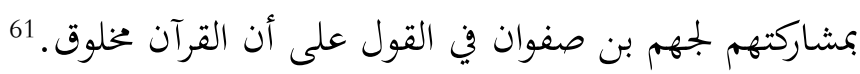
وقول المعتزلة في خلق القرآن، جائت نتيجة قولهم بان الله قديم، ولكي

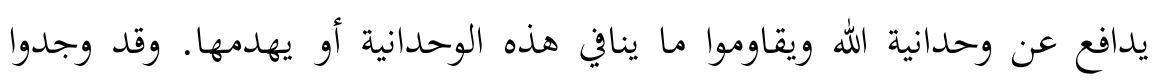
بالقول بأن القرآن غير مخلوق معنى الأزلية، والقدم والأزلية من صفات الله وحده. وقد تمادّوا في القول بخلق القرآن حتى جعلواه عديل التوحيد، ورموا من خالفه بالكفر والألحاد.

وممّا الذي جعل الجبرية والمعتزلة القول بخلق القرآن أمورٌ، منها:

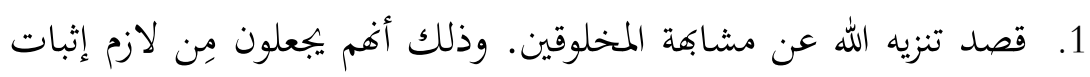
صفة الكلام إثبات صفات أخرى، وهي الحلق واللَّهَاة، واللسان

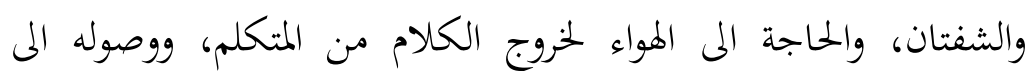

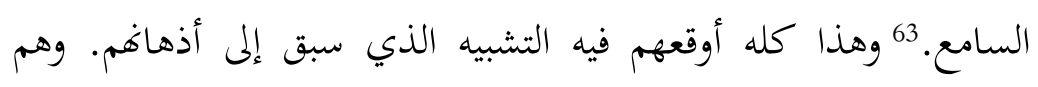

61 وأما قصد المعتزلة في نفي الصفات الإلمية فهو معارض للتصوّر اليهودي لله من جهة ولآراء

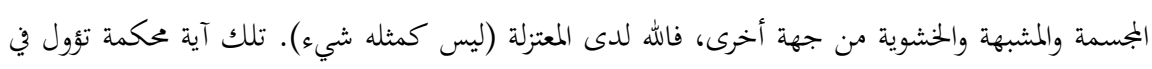

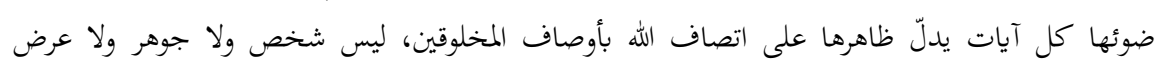

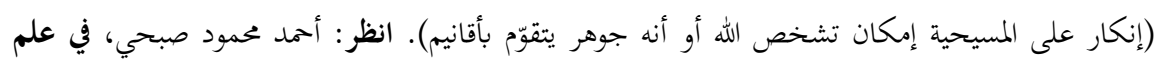
الكلام: دراسة فلسفية لآراء القرق الإسلامية في أصول الدين، ج.1، (بيروت: دار النهضة العربة العربية، 1985

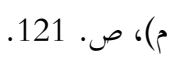
62 محمد إبراهيم الفيومي، الخوارج والمرجئة، (القاهرة: دار الفكر العربي، 2003 م)، ص. 282.

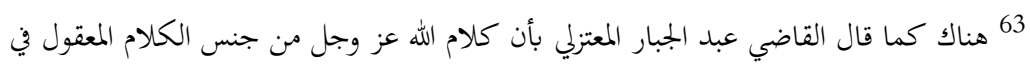
الشاهد وهو حروف منظومة وأصوات مقطوعة. هو عرض يخلق الله تعالى في الأجسام على وجه يسمع ويفهم

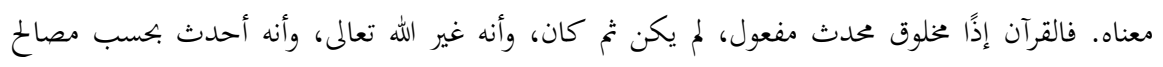


218 Rausyan Fikr, Vol. 17 No. 2 Desember 2021: 203 - 227.

شبّهوا بأذهاهم أولا، فاستقبحوا التشبيه. والآخر فدعاهم الى الوقوع في ضلالة، وهو تعطيل صفات الكالام. وقد بُنيَ التعطيل هنا على التشبيه في الأذهان. فهربوا من باطل، فوقعوا في باطل مثله.64 2. تنزيه الله عن حلول الحوادث به. فإهم يزعمون أن القول بإثبات صفة

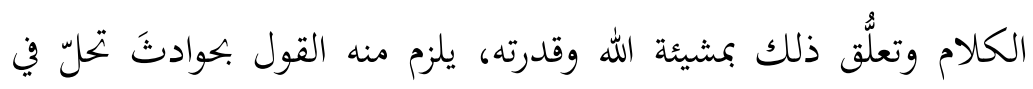
ذات الله. فيكون الله تعالى لا يخلو من الحوادث. وما لا يخلوا من الحوادث فهو حادث، والحوادث كلها خخلوقة عندهم. 65 3. كان الكلام مخلوقا، وكان صفةً فعليةً حادثةً متعلّقةً بمشيئة الله وقدرته. لكنّها تكون حينئذٍ مخلوقةً منفصلةً عن ذات الرب تعالى، حتى لا تحلّه الحوادث. وإلاّ، لكان هو حادثا مخلوقا. 66

ثانيا: وجه الإختلاوف

اختلف أهل السنة والجماعة عموما والإمام أحمد بن حنبل خصوصا من الجبرية والمعتزلة في مسألة خلق القرآن. إن الإمام أحمد استقرّ على أن القرآن غير مخلوق وهو كلام الله القديم الأزلي.

وكانت هذه المشكلة يعني القول بخلق القرآن تتعلق بصفات الله. ولِذِا فإن الإمام أحمد يثبت دائما على أن القرآن كلام الله حقيقة بكماله. و أن كلامه صفة من صفاته، كسمعه وبصره، ورحته وقدرته، وعفوه وغفرانه. فلا يجوز لأحد أن

64 عبد العزيز بن مرزوق الطرفي، الخراسانية في شرح عقيدة الرازيين، ص. 155.

$$
65 \text { نفس المرجع، ص. } 66 \text { نفس المرجع، ص. } 153 .
$$


يعتقد بخلق الصفات، لأن الصفات من الذات. فمن جعل صفة من صفاته مخلوقة، فقد جعل الموصوف - لله سبحانه وتعالى - مخلوقا.

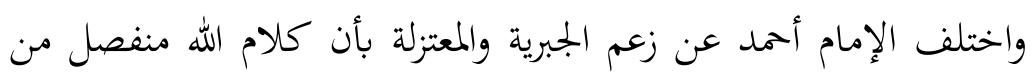

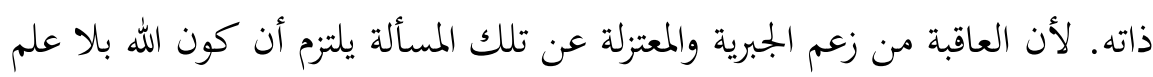
ولا معرفة عنده بشيء ولا اسم له ولا عزة له ولاصفة له. هذا من ضلال مبين، والله بريء من نقص وعجز.67 عند الإمام أحمد أن القرآن كلام الله، وكلامه صفة وله وده من صفاته، وصفاته ليست منفصلة عنه، ولا مخلوقة. 68 واختلف أيضا الإمام أحمد من رأي المعتزلة بخلق القرآن بأنه مقروء وهنهاه

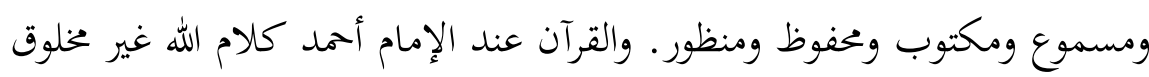
بكل جهة وعلى كل تصريف. وفي ذلك قال الإمام أحمد: "يتوجّه العبد لله بالقرآن بخمسة أوجه، وهو فيها غير مخلوق. يعني حفظ بقلب وتلب وتلاه بلسان وسمع بأذن ونظر بنظر وخطّ بيد. فالقلب مخلوق، والمحفوظ غير مخلوق. والتلاوة مخلوقة، والمتلو غير مخلوق. والسمع مخلوق، والمسموع غير مخلوق. والنظر مخلوق، والمنظور اليه غير مخلوق. والكتاب مخلوق، والمكتوب غير مخلوق. كان السلف الصالح يرد تأسيس نفي الصفات عند الجبرية والمعتزلة لأفم

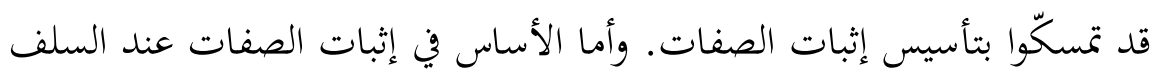
فهو وجوب المسلم أن يأمن بصفات الله وأسمائه كما وصّف الله نفسه في القرآن

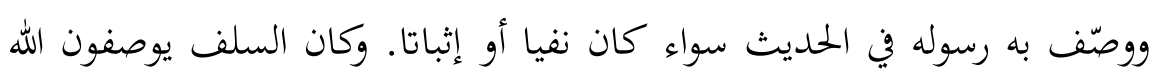

67 أحمد بن حنبل، الرد على الجهمية والزنادقة، ص. 122.

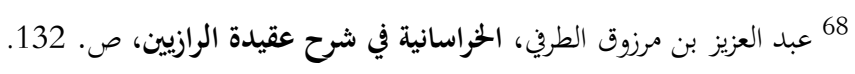

$$
69 \text { نفس المرجع، ص. } 149 .
$$


220 Rausyan Fikr, Vol. 17 No. 2 Desember 2021: 203 - 227.

كما وصّف الله نفسه ووصّف به رسوله دون تحريف ولا تعطيل، ودون تكييف ولا تمثيل. وأفم نفوا ما نفي الله عن نفسه وأثنتوا صفاته كما أثبت الله دون إلحاد، ليس في أسمائه ولا في آياته. 70 وهذا القضية يتعلق تقضية توحيد الأسماء والصفات. وشرح الإمام أحمد بن حنبل عن هذا التوحيد كما يلي:

1. ورود هذه الأسماء والصفات في الكتاب والسنة. فلا يثبت لله تعالى شيء

منها إلا ما أثبته في كتابه أو ما أثبت له رسوله صلى الله عليه وسلم، ويرجع ذلك إلى أن أسماء الله وصفاته توقيفية أي لا يثبت منها إلا ما ورد

$$
\text { في الشرع فحسب. }
$$

2. إفراد الله تعالى في معاني ما ثبت له من الأسماء والصفات بخواص تخلف عن الخواص التي تمييز بها المخلوق عن الخالق فيما له من الأسماء والصفات يعني اسماء الله تعالى وصفاته لاتشبيه شيئا من المخلوقين وصفاهم. فكل من المخلوق والخالق فإن اشترك في اللفظ الكلي فلا اشتراك بينهما في خواص وكيفيات الأسماء والصفات التي تقوم بكل منهـ

ونستطيع أن نأخذ النتيجة في تأسيس إثبات الصفات الإلهية عند السلف على أنه لايخرج من الكتاب والسنة وهما مصدر الإثبات والنفي، ولذلك لم يستند في إثبات الأسماء والصفات إلى مجرد العقل ولم يخرج من النص. فكل ما أثبت الله لنفسه من اسم وصفة وما أثبت له رسوله فإنه يثبت ذلك ويعتقده بلا تحريف ولا

70 تقي الدين أحمد بن عبد الحليم بن تيمية، الرسالة التدمرية، (القاهرة المطبعة :السلفي، 1400

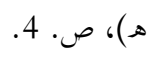


تشبيه ولا زيادة ولا نقصان. ودليله قوله تعالى (لَيْهنَ كَمِنْلِهِ شَيْهُ وَهُوَ السَّمِيْعُ

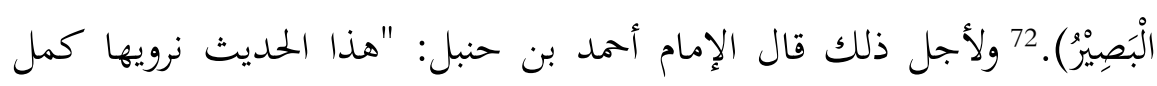
جائت"، وقال أيضا: "من صفات المؤمن إرجاء ما غاب عنه من الأمور إلى الله

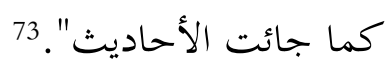

ثالثا: وجه النقدي

أن أهل السنة والجماعة ومنهم الإمام أحمد بن حنبل قد يردون ردا قطعية

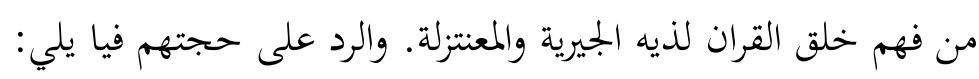

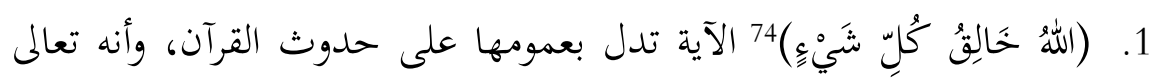

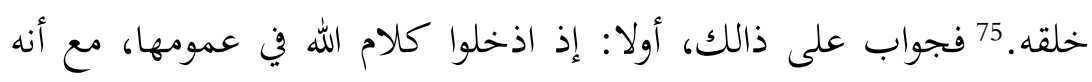

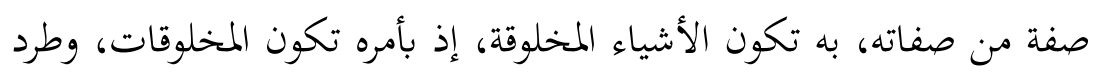
باطلهم: أن تكون جميع صفاته تعالى مخلوقة، كالعلم والقدرة، وغيرهما وذلك بك بكاء صريح. ثانيا: مراد من قول تعالى خالق كل شيء، أي كل شيء مخلوق، وكل

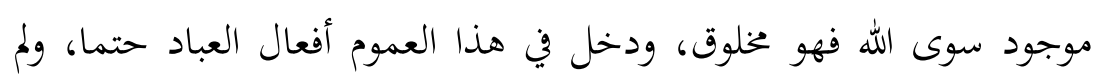
يدخل في العموم الخالق تعالى، وصفاته ليس غيره، لأنه سبحانه وتعالى هو

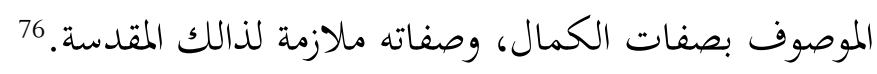

72 عبد العزيز السيلي، العقيدة السلفية بين الإمام أحمد بن حنبل والإمام ابن تيمية، (دار

$$
\text { المنار: القاهرة، } 1993 \text { م)، ص.176. }
$$

73 أبو الفرج ابن الجوزي، مناقب الإمام أحمد بن حنبل، (اسكندرية :دار ابن خلدون، 2016

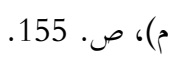

$$
\begin{aligned}
& \text { 74 سورة الرعد، آية } 16 .
\end{aligned}
$$

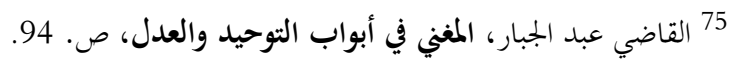

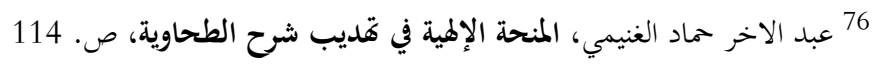


222 Rausyan Fikr, Vol. 17 No. 2 Desember 2021: 203 - 227.

2. بتأويل "جعل" بمعنى "خلق" فكل مجعول هو مخلوق.78 وقال الإمام أحمد: إذا قال الله "جعل" على معنَينِ. إما على معنى خلق ومعنى غير خلق. ومثال معنى

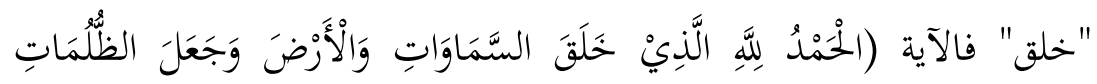

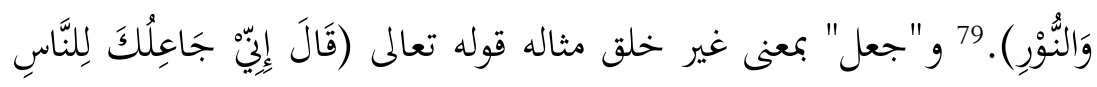
إمَامًا)80 لا يعني إني خالقك للناس إماما. لأن خلق إبراهيم كان متقدما قبل ذلك. 81 والبيان أيض عن ذلك، فإن "جعل" إذا كان بمعن خلق يتعدى إلى مفعول واحد. فإذا تعدى إلى مفعولين لم يكن بكعنى خلق.82 3. مهم كان الجبرية يزعمون أن القرآن سيّيَ بذِكِرٍ وهو محدث وكل محدث مخلوق

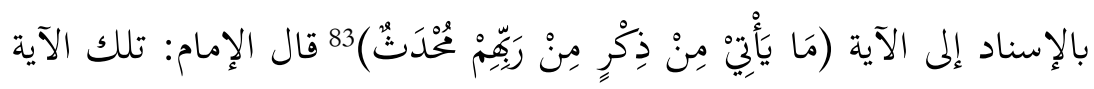
جمعت بين ذكرينِ. ذكر الله وذكر نبيه. وجرى عليهما اسم الحدث. وذكر وذر النبي إذا انفرد وقع عليه اسم الخلق وكان أولى بالحدث من ذكر الله الذي إذا انفرد لم يقع عليه اسم الخلق، ولا حدث.84 فوجد من هذه الآية أن النبي لا

$$
\begin{aligned}
& 77 \text { سورة الزخرف، آية } 3 .
\end{aligned}
$$

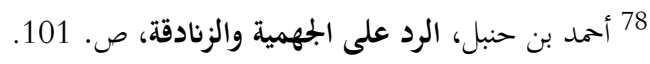

$$
\begin{aligned}
& 79 \text { سورة الأنعام، آية } 1 . \\
& 80 \\
& 81 \text { أحمد بن حنبل، المصدر السابق، ص. 102-105. }
\end{aligned}
$$

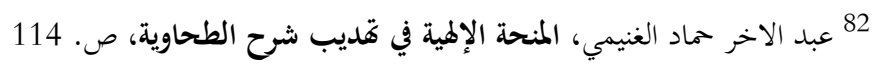

$$
83
$$

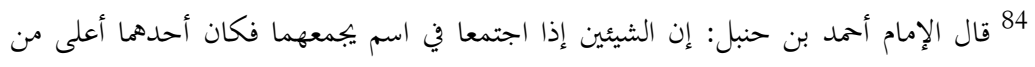

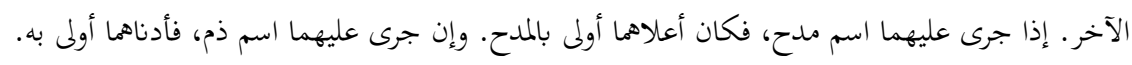


يعلم فعلّمه الله، فلمّا علمه الله كان ذلك محدِثا الى النبي صلى الله عليه

ونملم.85

والإستنتاج على تلك الاستدلالات أن هذه المشكلة تتعلق بصفات الله.

والبحث عن الصفات متصل بالتوحيد. ولذا فإنه يثبت دائما أن القرآن كلام الله

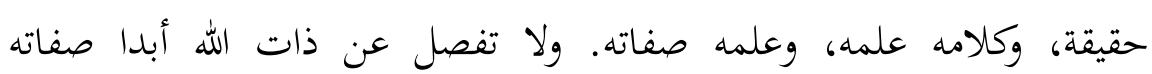
وأسمائه. 86

الترجيح

نحن نعرف من المناظرة والتعارضة الطويلة والردحة بين أهل السنة والجماعة

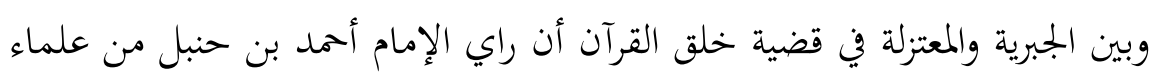

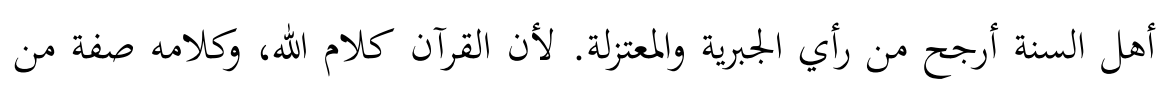

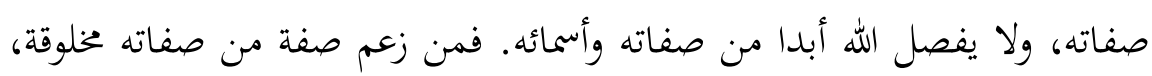

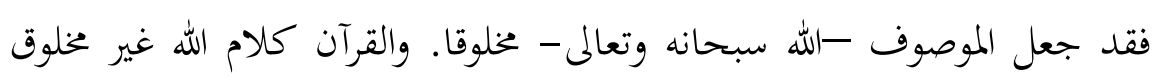
بكل جهة وعلى كل تصريف. وبالرغم هو مقروء ومسموع ومحفوظ ومنظور ومكتوب. لأنه لا يستوي بين فعل العبد وما قام به يعني القرآن.

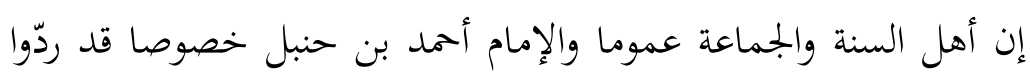

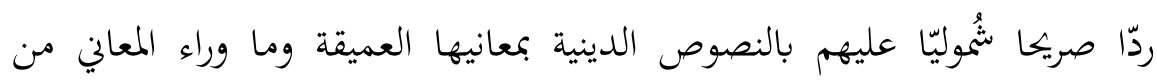

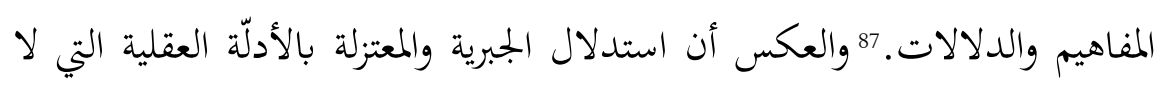

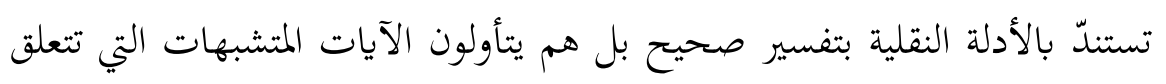

$$
\begin{aligned}
& 85 \text { أحمد بن حنبل، الرد على الجهمية والزنادقة، ص. } 125 . \\
& 86 \text { أمّل فتح الله زركشي، دراسة في علم الكلام، ص. } 224 . \\
& 87 \text { مصطفى حلمي، منهج علماء الحديث والسنة في أصول الدين، ص. }
\end{aligned}
$$


224 Rausyan Fikr, Vol. 17 No. 2 Desember 2021: 203 - 227.

وحقيقة الله تعالى وصفاته. هذا التأويل يسمى بالتأويل الكلامي.88 وقد ردّ السلف

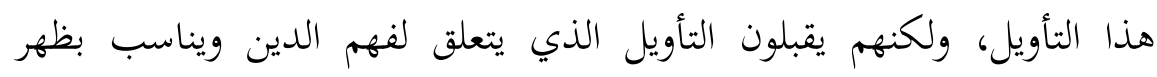
اللفظ.89

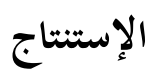

أن المشكلة في القول بخلق القرآن تتعلّق بصفات الله. واختلف أهل السنة

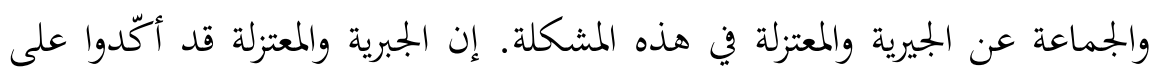

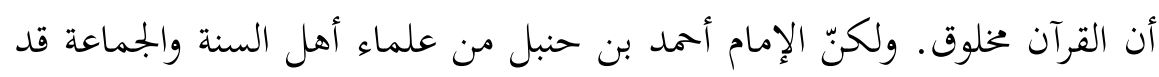
قرّر على أن القرآن غير مخلوق لأن القرآن كلام الله، وكلامه صفة من صنام صفاته،

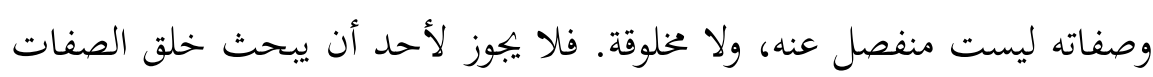
لأن الصفات من الذات. فمن جعل صفة من صفاته مخلوقة، فقد جعل الموصوف لمكن - الله سبحانه وتعالى - مخلوقا.

88 في العادة يأخذ المتكلمون والفلاسفة الدليل النقلي للاستدلال إذا يطابق بريهم، ولكن ينفون

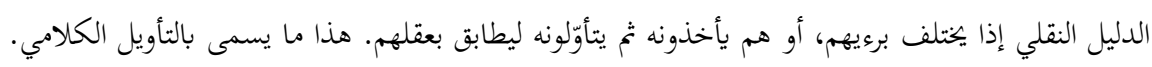

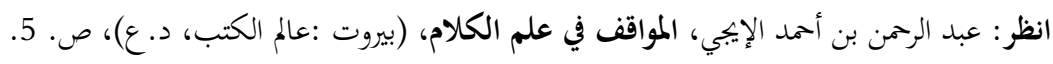

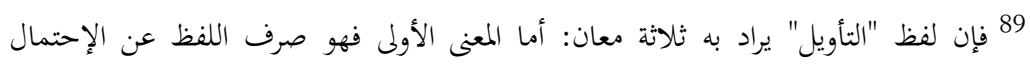

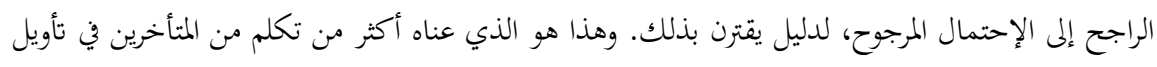

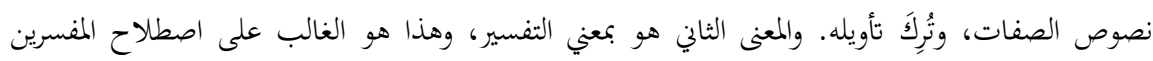

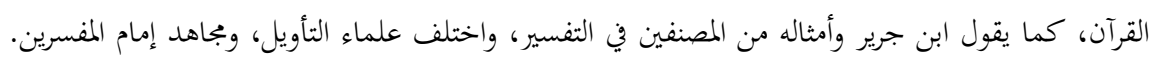

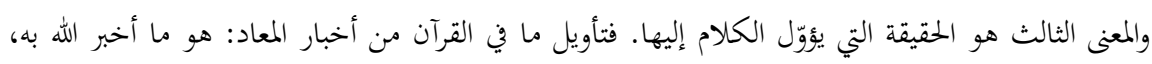

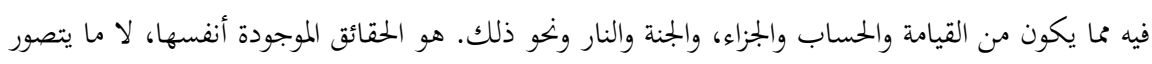

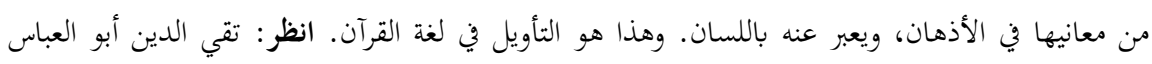

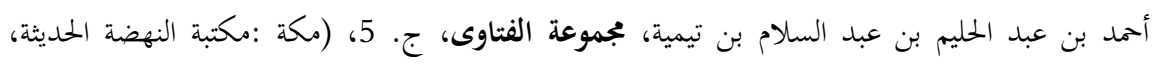
1404 هـ)، ص. 35 هـ 
وأما الجبرية والمعتزلة فقد أكّدوا بأن القرآن مخلوق. هم لا يقولون بأن الله متكلم وكلامه ذاته، خشيةً أن يتساوي كلام الله عز وجل مع ذاته. فيكون هناك قديمان مما يؤدي المى الشرك. ولما كان الله تعالى منزّها عن الصفات، في نظر الجبرية والمعتزلة فلا بد أن يتفقا على القول بخلق القرآن. وأرجح القول هو قول الإمام أحمد بن حنبل من أهل السنة والجماعة. لأنه قد استدلّ بالنصوص الدينية بتفسير صحيح وما ورائه من المفاهيم والدلالات.

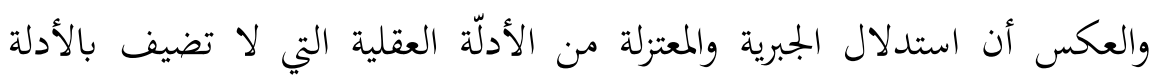
النقلية بتفسير صحيح. قائمة المراجع ابن الجوزي، أبو الفرج. 2016 م. مناقب الإمام أحمد بن حنبل. اسكندرية :دار

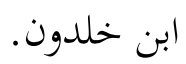

ابن تيمية، أحمد بن عبد الحليم بن عبد السلام. 1399. أصول التفسير. القاهرة: المكتبة السلفية. 1400 هـ. الرسالة التدمرية. القاهرة المطبعة :السلفي. 1404 هـ. مجموعة الفتاوى. ج. 5. مكة :مكتبة النهضة الحديثة.

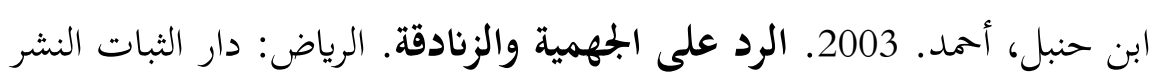
والتوزيع.

ابن عبد المعتق، عوّاد. 1414. المعتزلة وأصولهم الحمسسة وموقف أهل السنة منها. الرياض: مكتبة الرشد. ابن منظور. 2009. لسان العرب. ج. 11. بيروت: دار الكتب العلمية. 
226 Rausyan Fikr, Vol. 17 No. 2 Desember 2021: 203 - 227.

أبو زهرة، حمد. د.ع. ابن حنبل :حياته وعصره، أراءه وفقهه. القاهرة: دار الفكر العربي.

أبو زيد، نصر حامد. 1994. نقد الحطاب الديني. القاهرة: سينا للنشر. أبو زيد، نصر حامد. 2014. مفاهم النص: دراسة في علوم القرآن. بيروت:

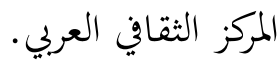
أمين، أحمد. 1973. ضحى الإسلام. القاهرة: النحضة المصرية.

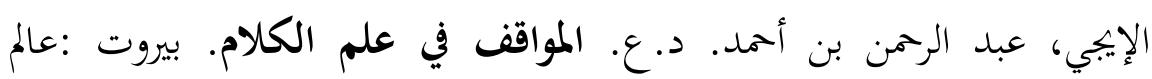

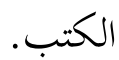
البخاري، محمد بن إسماعيل، 1422هـ. صحيح البخاري. دمشق: دار طوق

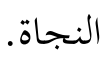

بكر إسماعيل، محمد. 1991. دراسة في علوم القرآن. القاهرة: دار المنار. الجرجاني. د.ع. معجم المعرفة. القاهرة: دار الفضيلة. حلمي، مصطفى. 1971. منهج علماء الحديث والسنة في أصول الدين. بيروت: دار الكتب العلمية.

الراجحي، عبد العزيز عبد الله. 1434. شرح أصول السنة للإمام أحمد بن حنبل. الرياض: دار التوحيد للنشر.

زركشي، أمّل فتح الله. 2016. دراسة في علم الكلام. فونوروكو: جامعة دار السلام كوتور للطباعة والنشر.

الزهيلي، وهبة. 1996. الوجيز في أصول الفقه. بيروت: دار الفكر. السيلي، عبد العزيز. 1993 م. العقيدة السلفية بين الإمام أحمد بن حنبل برول والإمام ابن تيمية. دار المنار: القاهرة. 
|قضية خلق القرآن عند الجببرية ... Amir Sahidin, Abdul Rohman,

صبحي، أحمد محمود. 1980 م. في علم الكلام: دراسة فلسفية لآراء القرق الإسلامية في أصول الدين. ج.1. بيروت: دار النهضة العربية.

الطرفي، عبد العزيز بن مرزوق. 2016. الحراسانية في شرح عقيدة الرازيين. ج.1. د.م: مكتبة المنهاج.

عبد الجبار، القاضي. 1961. المفني في أبواب التوحيد والعدل. ج. 7. القاهرة: دار التراث.

الغنيمي، عبد الاخر حماد ـ 1995. المنحة الإلمية في قَديب شرح الطحاوية.

$$
\text { بيروت: دار ابن الجوزي }
$$

الفيّومي، محمد إبراهيم. 2003. الحوارج والمرجئة. القاهرة: دار الفكر العربي.

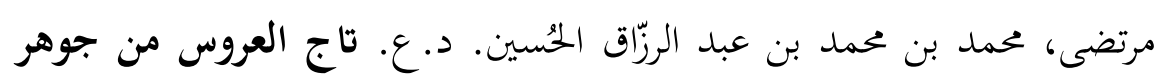
القاموس. د.م: دار الهداية. 